\title{
Lipid Mediators in Critically III Patients: A Step Towards Precision Medicine
}

\author{
Luca Cioccari $^{1,2}$, Nora Luethi ${ }^{2,3}$ and Mojgan Masoodi ${ }^{4 *}$ \\ 1 Department of Intensive Care Medicine, Inselspital, Bern University Hospital, Bern, Switzerland, ${ }^{2}$ Australian and New \\ Zealand Intensive Care Research Centre, School of Public Health and Preventive Medicine, Monash University, Prahran, VIC, \\ Australia, ${ }^{3}$ Department of Emergency Medicine, Inselspital, Bern University Hospital, Bern, Switzerland, ${ }^{4}$ Institute of Clinical \\ Chemistry, Inselspital, Bern University Hospital, Bern, Switzerland
}

OPEN ACCESS

Edited by:

Juan Bautista De Sanctis, Palacký University Olomouc, Czechia

Reviewed by:

Charles C. Caldwell, University of Cincinnati, United States

Philip Calder,

University of Southampton,

United Kingdom

*Correspondence:

Mojgan Masoodi

mojgan.masoodi@insel.ch

Specialty section: This article was submitted to Cytokines and Soluble Mediators in Immunity, a section of the journal

Frontiers in Immunology

Received: 28 August 2020

Accepted: 26 October 2020

Published: 25 November 2020

Citation:

Cioccari L, Luethi N and Masoodi M (2020) Lipid Mediators in Critically III Patients: A Step Towards Precision Medicine.

Front. Immunol. 11:599853. doi: 10.3389/fimmu.2020.599853
A dysregulated response to systemic inflammation is a common pathophysiological feature of most conditions encountered in the intensive care unit (ICU). Recent evidence indicates that a dysregulated inflammatory response is involved in the pathogenesis of various ICU-related disorders associated with high mortality, including sepsis, acute respiratory distress syndrome, cerebral and myocardial ischemia, and acute kidney injury. Moreover, persistent or non-resolving inflammation may lead to the syndrome of persistent critical illness, characterized by acquired immunosuppression, catabolism and poor long-term functional outcomes. Despite decades of research, management of many disorders in the ICU is mostly supportive, and current therapeutic strategies often do not take into account the heterogeneity of the patient population, underlying chronic conditions, nor the individual state of the immune response. Fatty acid-derived lipid mediators are recognized as key players in the generation and resolution of inflammation, and their signature provides specific information on patients' inflammatory status and immune response. Lipidomics is increasingly recognized as a powerful tool to assess lipid metabolism and the interaction between metabolic changes and the immune system via profiling lipid mediators in clinical studies. Within the concept of precision medicine, understanding and characterizing the individual immune response may allow for better stratification of critically ill patients as well as identification of diagnostic and prognostic biomarkers. In this review, we provide an overview of the role of fatty acid-derived lipid mediators as endogenous regulators of the inflammatory, anti-inflammatory and pro-resolving response and future directions for use of clinical lipidomics to identify lipid mediators as diagnostic and prognostic markers in critical illness.

Keywords: critical illness, inflammation, resolution of inflammation, lipidomics, fatty acid-derived lipid mediators 


\section{INTRODUCTION}

Systemic inflammation is a common pathophysiological feature of many conditions encountered in the intensive care unit (ICU). A key determinant of the outcome in critically ill patients is the balance of pro- vs. anti-inflammatory pathways and the body's capability to resolve the acute inflammation and restore homeostasis. An appropriate and timely inflammatory response protects the body from the injurious agent and eliminates the threat without causing collateral damage. However, a dysregulated inflammatory response can contribute to multiple organ dysfunction and early in-hospital death $(1,2)$.

Fatty acid-derived lipid mediators play a pivotal role in the endogenous regulation of infection and inflammation $(3,4)$. In recent years, the resolution of inflammation and restoration of homeostasis has been recognized as an active process. Specialized pro-resolving mediators (SPMs) derived from polyunsaturated fatty acids (PUFA) have been detected as key signaling molecules in the resolution of inflammation and play an important role in dampening the inflammatory response without causing immunosuppression $(5,6)$.

The human immune response is complex, highly variable and unpredictable, and ICU patients represent an exceptionally heterogeneous population. There is a growing recognition that treating ICU patients requires a more personalized approach. Precision medicine offers a strategy for prevention and treatment of disease based on characteristics of each individual to maximize effectiveness, and, therefore, can overcome some challenges associated to ICU patients (7-11). In addition to genetics and clinical data often used in precision medicine (12), assessing metabolism using metabolomics and lipidomics can provide valuable information for further phenotyping and characterization of patients. Lipidomics provides a powerful tool to assess lipid metabolism and identify specific lipid profiles in such patients $(3,13-15)$, thus providing unique insights into the individual immune response. Identification of such metabolic signatures could improve prognostic and diagnostic evaluation and pave the path to personalized treatment strategies.

In this review, we address the role of fatty acids-derived bioactive lipid mediators and their prognostic, diagnostic and therapeutic potential in frequently encountered intensive-care related conditions.

\section{FATTY ACID-DERIVED LIPID MEDIATORS: ENDOGENOUS REGULATORS OF INFLAMMATION AND RESOLUTION}

In the normal immune response, the acute inflammation is followed by successful resolution and repair of tissue damage. However, upon dysregulation of the immune response, persistence of inflammation leads to immune suppression and organ failure $(16,17)$. Inflammatory insults such as tissue damage or microbial invasion activate cells of the innate immune system like macrophages and dendritic cells to initiate a nonspecific immune response (18) which leads to rapid influx of immune cells, mainly neutrophils and monocytes, followed by monocyte differentiation into inflammatory macrophages. This process is orchestrated by proinflammatory lipid mediators such as eicosanoids (e.g., prostaglandins and leukotrienes), cytokines (e.g., TNF, IL-1, IL-6), and chemokines (19) (Figure 1A). Prostaglandins are produced by most cells in our body and act as autocrine and paracrine lipid mediators upon stimulation (e.g., mechanical trauma, growth factor, cytokines), while leukotrienes are produced predominantly by inflammatory cells like macrophages, polymorphonuclear leukocytes, and mast cells (20). Pro-inflammatory prostaglandins like prostaglandin E2 (PGE2) and leukotriene B4 (LTB4) initiate and contribute to the characteristic inflammatory response which includes vascular dilation, vascular permeability and edema $(21,22)$.

Resolution of inflammation is highly dependent on the signaling network generated during this process as well as alterations in number of lymphocytes and phenotype of macrophages (23). The acute inflammatory response is normally terminated once the triggering insult is eliminated. However, when excess neutrophils congregate, they can cause additional tissue damage, and sometimes lead to unresolved chronic inflammation (3, 24-26) (Figure 1A).

In recent years, the resolution of inflammation and restoration of homeostasis have been recognized as active processes, regulated by a superfamily of endogenous lipid mediators, namely specialized proresolving mediators (SPMs). SPMs include $\omega-6$ arachidonic acid-derived lipoxins, $\omega-3$ eicosapentaenoic acid (EPA) and docosahexaenoic acid (DHA)-derived resolvins, protectins and maresins $(4,27,28)$ (Figure 1B). These novel immunoresolvents are key signaling molecules in the resolution of inflammation, enhancement of bacterial clearance, and play an important role in dampening the inflammatory response $(29,30)$.

PGE2 not only stimulates LTB4-mediated polymorphonuclear neutrophil (PMN) recruitment to sites of inflammation but also initiates resolution of inflammation by stimulating 15lipoxygenase (LOX)-dependent lipoxin production in neutrophils $(22,31)$. Lipoxin then stimulates further production of other SPM (32), such as resolvins and protectins (33). Lipoxygenation and epoxidation of DHA lead to biosynthesis of maresins (macrophage mediators in resolving inflammation) which, in turn, regulate the production of the leukocyte chemoattractant $\mathrm{LTB}_{4}$ (34). At the cellular level, lipoxins and resolvin E1 (RvE1) are potent stopping signals for further neutrophilic infiltration $(35,36)$. To remove the already infiltrated neutrophils from the tissue, Lipoxin $\mathrm{A}_{4}\left(\mathrm{LXA}_{4}\right)$ also stimulates macrophage efferocytosis (phagocytosis of apoptotic neutrophils and cell debris) (3). Epoxy lipid mediators generated via CYP450 have also been reported to limit the accumulation of inflammatory monocytes during resolution and exhibit a critical role in monocyte lineage recruitment and resolution (37).

Beyond innate phagocyte responses to resolve acute inflammation, SPMs appear to play critical roles in regulating adaptive immunity. SPMs selectively regulate cytokines via specific SPM receptors expressed on innate lymphoid, NK-, T-, and B cells (24).

SPM restrain inflammation and resolve infection, and each SPM family member possesses potent pro-resolving and anti- 


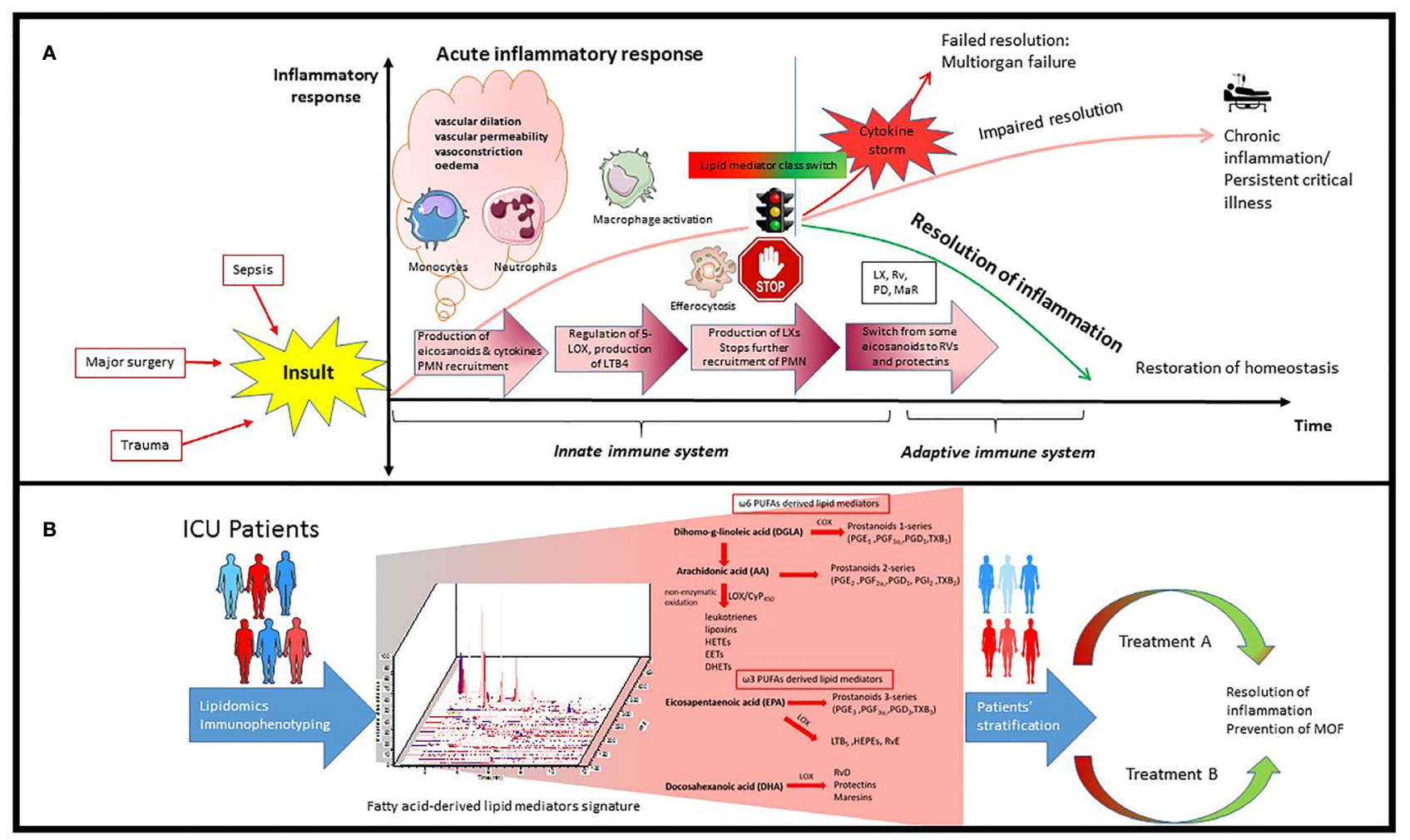

FIGURE 1 | Schematic process of inflammatory response in ICU patients and how it can be used for precision medicine. (A) Inflammatory insults like bacterial infection and trauma leads to rapid influx of immune cells, mainly neutrophils and monocytes, followed by monocyte infiltration and differentiation to inflammatory macrophages. This process is orchestrated by pro-inflammatory lipid mediators such as eicosanoids and cytokines. Resolution of inflammation is highly dependent on the signaling network generated during this process as well as alteration in number and phenotype of macrophages and lymphocytes. PGE2 can also activate the regulation of 15-LOX in human neutrophils, which leads to production of lipoxins and stops further recruitment of PMN. There is an active switch from production of some eicosanoids to resolvins and protectins which initiates the resolution of inflammation. (B) Lipidomics provides a powerful tool to identify and quantify hundreds of fatty acid-derived lipid mediators simultaneously potentially participating and contributing to inflammation and its resolution which leads to identification of specific signatures in ICU patients. Integrating transcriptomics, proteomics and lipidomics could further advance our understanding of this complex network during infection in ICU patients, leading to better patient stratification and personalized treatment.

inflammatory actions [reviewed in (3)] with specific functions in the resolution phase (24). Several reports in experimental models demonstrated important roles for SPMs in promoting a return to homeostasis after infection or injury, leading to improved outcomes and survival (38). Table S1 summarizes lipid mediators in animal models of intensive care-related conditions. Defects in SPM pathways impair the coordinated resolution of inflammation and could be implicated in the dysregulated inflammatory response encountered in many ICU-related conditions. Nevertheless, further and stronger evidence is needed to clarify the effects and potential role of SPMs in critical care.

\section{LIPID MEDIATORS IN INTENSIVE CARE- RELATED CONDITIONS}

\section{Sepsis}

The hallmark of sepsis is a dysregulated host response to infection. Sepsis is defined as infection-related organ dysfunction, and septic shock is further complicated by refractory hypotension with elevated blood lactate levels (39-41). The pathophysiology of sepsis is extraordinarily complex (42). Various molecules originating from the infecting microorganism, so-called pathogen-associated molecular patterns (PAMPs), or from necrotic cells, the damage-associated molecular patterns (DAMPs) activate the innate immune system through pattern recognition receptors on leukocytes, leading to a signaling cascade eventually resulting in the generation of pro-inflammatory cytokines. This "cytokine storm" is likely responsible for the systemic inflammatory response and the resulting organ dysfunction (induced by both cellular infiltration and ischemia) characteristic of sepsis. As numerous attempts aiming to dampen this cytokine storm have failed in clinical trials (43), considerable challenges remain in the management of sepsis.

Administration of SPM has shown some promising results in animal models of sepsis; however, this approach has not yet been translated into clinical practice. In animal studies, administration of D-series resolvins counter-regulates proinflammatory genes, 
decreases excessive cytokine production, neutrophil recruitment and infiltration, and enhances phagocytosis of bacteria, reducing tissue damage and improving survival (44-51). Exogenous administration of maresins $(52,53)$ and lipoxins has similar effects (54-58).

Published human studies to date are mainly observational (Table 1). In addition, some clinical studies investigated aspirintriggered resolvins and lipoxins. In healthy adults, low-dose aspirin stimulates biosynthesis of anti-inflammatory mediators (69) and, in ICU patients with a severe inflammatory response, it reduces the concentration of proinflammatory mediators (17HETE, 18-HETE, and 20-HETE) and increases the concentration of the anti-inflammatory mediators 17,18-DiHETE and 14,15DiHETE (60). However, Dalli et al. reported significantly higher levels of pro-resolving mediators like RvE1, RvD5 and 17R-PD1 in sepsis non-survivors compared to survivors (61). It is therefore arguable that higher levels of SPM might be harmful rather than useful. One possible explanation for this apparent contradiction is that, in sepsis non-survivors, the endogenous increase in SPM may not be sufficient to reverse the inflammatory process or perhaps the time window in which these mediators are produced is critical. Moreover, the increased levels of pro-inflammatory cytokines observed in non-survivors (61) suggest more severe systemic inflammation, where, although increased, SPM levels are not sufficient to resolve the ongoing inflammation. This hypothesis has also been supported by Abdoulnour and colleagues, who found that increased plasma 15-epi-LXA4 levels at baseline were associated with development of ARDS, indicating engagement of counter-regulatory pathways that were ultimately insufficient to prevent the development of ARDS in these patients (63). Finally, many SPM possess dual biological actions and their effect may change over time, as exemplified by the study of Sordi et al. (58): In mice, LXA4 was increased at the beginning of sepsis, contributing to the harmful excessive inflammatory response. However, LXA4 administered in late sepsis was beneficial to the animal, controlling the excessive inflammation. These data suggest that both antagonizing LXA4 actions in the beginning or its administration in later periods could be beneficial in sepsis treatment.

\section{Acute Respiratory Distress Syndrome (ARDS)}

Acute respiratory distress syndrome (ARDS) is characterized by a non-cardiogenic pulmonary edema (70), caused either by pulmonary or extrapulmonary events including severe pneumonia, sepsis, aspiration of gastric content, and trauma. The resulting acute lung injury is driven by excessive

TABLE 1 | Clinical lipidomics (or studies) of fatty acid-derived lipid mediators in intensive care-related conditions.

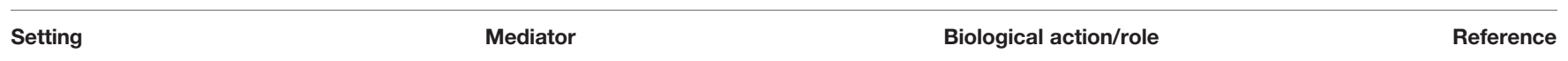

\section{Sepsis /SIRS}

66 patients with sepsis

20 healthy controls

$\mathrm{RCT}$ of Aspirin (ASA) vs placebo

48 patients with SIRS ( $n=32$ with lipid analyses)

22 patients with sepsis

\section{Acute lung injury/ARDS}

Substudy of the LIPS-A trial (62), RCT of ASA vs placebo for prevention of ARDS: 345 patients at risk for ARDS

21 patients with ARDS

16 patients with ARDS

Traumatic brain injury (TBI)

15 patients with TBI

73 healthy controls

\section{Lipoxin}

Resolvins, Protectins

Maresins, Lipoxins

Leukotriene

Resolvins, Protectins

PDX

Thromboxane B2 (TXB2) Aspirin-triggered lipoxin A4 (ATL)

TXB2, prostaglandin F1alpha (PGF1-alpha) and leukotriene B4 (LTB4)

TXB2, 6-keto prostaglandin F(1alpha), and LTB4

Free fatty acid (FFA) concentrations in cerebrospinal fluid (CSF)

\section{Trauma}

100 trauma patients 20 healthy controls 96 trauma patients 28 healthy controls

Leukotriene $\mathrm{B}_{4}$

Lipid mediator gene pathways
- Baseline LXA 4 levels were lower in sepsis patients (vs healthy controls) but not associated with 28-day mortality.

- ASA increased serum concentration of 15-HETE (LXA4 precursor) and antiinflammatory mediators 17,18-DiHETE and 14,15-DiHETE.

- ASA reduced the concentration of the proinflammatory mediators 17-HETE, 18HETE, and 20-HETE.

- Higher 10S,17S-diHDHA (PDX) at day 3 predicted ARDS development.

- Higher inflammation-initiating mediators (PGF2 $\alpha$, LTB4) and pro-resolving mediators (RvE1, RvD5, and 17R-PD1) in non-survivors.

- ASA significantly decreased TXB2 and increased the plasma ATL/TXB2 ratio.

- Elevated ATL associated with ARDS.

- Plasma levels of eicosanoids higher in ARDS patients.

- LTB4 correlated with the severity of respiratory failure.

- LTB4 correlated with lung-injury severity and outcome.

- CSF concentration of all FFAs significantly higher in TBI patients.

- Individual concentrations of arachidonic, myristic, and palmitic acids at 1 week significantly lower in patients with favorable early outcome compared to patients with worse outcome ratings at the time of hospital discharge.

- Elevated $\mathrm{LTB}_{4}$-levels at admission predicted risk of pulmonary complications.

(67)
- Higher resolvin pathway gene expression and lower gene expression ratio of leukotriene:resolvin pathways in patients with uncomplicated recovery.

ARDS, Acute Respiratory Distress Syndrome; ASA, acetylsalicylic acid; ATL, Aspirin-triggered lipoxin; CSF, cerebrospinal fluid; diHDHA, Dihydroxy-docosahexaenoic acid; DiHETE, Dihydroxy-eicosatetraenoic acid; FFA, free fatty acids; HETE, Hydroxyeicosatetraenoic acid; LT, Leukotriene; MaR, Maresin; PD, Protectin; PG, Prostaglandin; RCT, randomized controlled trial; Rv, Resolvin; SIRS, Systemic Inflammatory Response Syndrome; TBI, Traumatic brain injury; TX, Thromboxane. 
inflammation as a consequence of an imbalance of proinflammatory and anti-inflammatory cytokines, with release of multiple mediators of inflammation into the alveolar space and into the bloodstream (71). Increased endothelial and epithelial permeability then leads to alveolar fluid accumulation and impaired gas exchange. Resolution of ARDS requires endothelial and epithelial repair and reabsorption of alveolar edema fluid, and SPM are an essential component of the resolution program (72). Despite improvements in clinical management, mortality remains high and there is no specific treatment, nor are there universally agreed-upon biomarkers for survival and outcome in ARDS.

Different types of acute lung diseases have distinct lipid profiles (73) and lipid mediators may represent useful prognostic markers in critically ill patients. LTB4 correlates with lung-injury severity and outcome in patients with ARDS $(64,65)$ and higher pro-inflammatory mediators like PGF2 $\alpha$ and selected pro-resolving mediators like 10S,17S-diHDHA were predictive of ARDS development in patients with sepsis (61). In patients at risk for ARDS randomized to aspirin versus placebo, increased levels of aspirin-triggered lipoxin A4 (15epi-LXA4) were associated with the development of ARDS (63).

In animal models, administration of SPM has particularly beneficial effects in injured lungs (74). Maresins have organ protective effects, decrease edema, improve lung mechanics and tissue hypoxia (75). RvD1 decreases pulmonary edema, leukocyte infiltration and the release of pro-inflammatory cytokines and alleviates lung injury (76-79) and RvE1 can restore mitochondrial function in human alveolar epithelial cells and accelerates the resolution of experimental lung inflammation (80-82). Moreover, protectin D1 has beneficial effects in influenza-infected mice (83) and 15-epiLXA4 inhibits neutrophil infiltration and enhances pathogen clearance $(84,85)$.

\section{Trauma, Traumatic Brain and Spinal Cord Injury}

Major trauma is a leading cause of morbidity and mortality around the globe $(86,87)$. Severe traumatic injury has a considerable impact on the immune and metabolic system (88, 89) and leads to a posttraumatic cascade of inflammatory changes (90-93). Therefore, lipid mediators have been proposed as prognostic markers in trauma patients $(67,68,94)$. In patients with traumatic brain injury (TBI), cerebrospinal fluid concentration of free fatty acids is significantly elevated and correlates with clinical outcomes (66).

Accumulating evidence from animal studies suggests that various lipid mediators may have a role as therapeutic agents in cerebral and spinal cord injury. Elovanoids are derivatives from very long chain PUFAs and have neuroprotective properties in animal models of TBI and ischemic stroke (95, 96). In other animal models of TBI, RvD1 promotes functional recovery and halts glial activation and neuronal death, and RvE1 modulates the inflammatory response $(97,98)$. Moreover, parenteral or enteral administration of DHA reduces lesion size and axonal injury in rodents with TBI (99-101). The effect of DHA administration in rats with spinal cord injury has recently been summarized in a systematic review and metaanalysis (102). The reported studies suggest that, in rats, DHA can promote motor functional recovery after spinal cord injury. This effect appears limited to administration of DHA, and is not observed with EPA (103). Finally, Maresin 1 also improves neurological outcomes after experimental spinal cord injury (104). Although these findings are encouraging, further validation with adequate animal models are needed, taking into consideration the dose, target specificity and central nervous system penetration of tested compounds.

\section{Cerebral Ischemia and Reperfusion: Ischemic Stroke and Cardiac Arrest}

Ischemia/reperfusion injury is a major determinant of poor outcome in patients with ischemic stroke and cardiac arrest survivors (105). In cardiac arrest, global cerebral ischemia alters cell metabolism and the balance of cerebral vasodilator/ vasoconstrictor eicosanoids, rendering the cells susceptible to further damage after reperfusion: Vasoconstrictor eicosanoids are increased, and inhibition of 20-HETE synthesis (a potent vasoconstrictor) improves cortical perfusion and short-term neurologic outcome in a rat model of cardiac arrest (106).

In ischemic stroke, various in vitro and in vivo studies demonstrated that SPMs reduce leukocyte infiltration and neuronal injury, enhance efferocytosis and decrease both the production of inflammatory cytokines and oxidative stress (107). Cerebral artery occlusion and reperfusion causes significant reduction in endogenous RvD2 levels, and treatment with RvD2 reduces cerebral infarction, inflammatory cytokines, edema and neurological dysfunction (108). In another animal model, RvD1 promotes functional recovery, reduces neuroinflammation and prevents neuronal cell death (109). Neuroprotectin D1 (NPD1) down-regulates apoptosis and promotes cell survival $(110,111)$, and the administration of its precursor DHA has similar beneficial effects in experimental stroke (112-114). Additional administration of aspirin leads to cerebral synthesis of aspirin-triggered NPD1 (AT-NPD1), which reduces infarct size and significantly improves neurological scores in rats (110).

\section{Myocardial Infarction}

As with stroke, ischemia/reperfusion plays a pivotal role in the pathophysiology of myocardial infarction and contributes to up to $50 \%$ of the final infarct size (115). A crucial aspect is the balance between vasoconstrictive and vasodilatory metabolites of arachidonic acid (116). Vasodilating epoxyeicosatrienoic acids (EETs) have cardioprotective effects $(117,118)$, and increasing EETs via administration of selective soluble epoxide hydrolase inhibitors shows beneficial effects in animal models of ischemia/ reperfusion injury (119-122). Moreover, lipoxin administration post myocardial infarction improves left ventricular ejection fraction in mice (123). RvD1 promotes the resolution of acute inflammation initiated by myocardial infarction and has renoprotective effects, delaying the onset of heart failure and cardiorenal syndrome $(124,125)$. Finally, RvE1 prevents apoptosis in cardiac myocytes exposed to ischemia/reperfusion and decreases infarct size in rats (126). These experimental data 
suggest a potential for therapeutic use of SPMs in patients with myocardial infarction, however, no clinical studies have been published to date.

\section{Acute Kidney Injury (AKI)}

Acute kidney injury (AKI), a frequent complication of critical illness, occurs in more than $50 \%$ of ICU patients (127). As management of AKI is largely supportive, early identification of patients at risk is of paramount importance. Several novel biomarkers for early detection of kidney damage have been identified (127), but limitations in specificity and sensitivity have prevented their clinical application. As early lipid changes are involved in the pathogenesis of AKI $(128,129)$, lipidomic analysis offers-once more-a promising approach for identifying diagnostic and prognostic biomarkers (130). Moreover, SPM have been studied as potential therapeutic agents in AKI due to their organ-protective properties in ischemia/reperfusion (131). In mice, administration of RvD or PD1 before an ischemic insult results in reduced functional and morphological kidney injury $(132,133)$ and aspirin-triggered resolvin D1 down-regulates the inflammatory response and protects against endotoxin-induced AKI (134).

In summary, analysis and characterization of specific lipid mediator profiles has the potential to improve diagnostic and prognostic accuracy in various conditions commonly encountered in the ICU. Numerous experimental studies provide a theoretical basis for therapeutic administration of lipid mediators in specific circumstances. However, translation from bench to bedside is still in its infancy.

\section{CONCLUSION AND FUTURE DIRECTIONS}

Systemic inflammation is a common pathophysiological trait of many conditions leading to critical illness. While a certain degree of inflammation is protective, a dysregulated inflammatory response is detrimental, contributing to multiple organ failure and death. Many clinical trials of treatments aiming at modulating the inflammatory response in ICU patients have failed to improve outcomes, partly due to the tremendous complexity and heterogeneity of critical illness. Hence, there is growing interest in personalized treatment in ICU patients (711). In past decades, the complexity of the human inflammatory response may have been under-recognized, and previous experimental and clinical models may not accurately represent

\section{REFERENCES}

1. Kotas ME, Medzhitov R. Homeostasis, inflammation, and disease susceptibility. Cell (2015) 160(5):816-27. doi: 10.1016/j.cell.2015.02.010

2. Angus DC, van der Poll T. Severe sepsis and septic shock. $N$ Engl J Med (2013) 369(9):840-51. doi: 10.1056/NEJMra1208623

3. Serhan CN. Pro-resolving lipid mediators are leads for resolution physiology. Nature (2014) 510(7503):92-101. doi: 10.1038/nature13479

4. Dennis EA, Norris PC. Eicosanoid storm in infection and inflammation. Nat Rev Immunol (2015) 15(8):511-23. doi: 10.1038/nri3859 human pathobiology (135-137). Lipidomics has attracted a lot of attention in recent years due to its ability to assess lipid metabolism and comprehensively characterize different molecular lipid species in different pathophysiological conditions. Recent advances in lipidomic research have highlighted the role of fatty acid-derived lipid mediators as key players in generation and resolution of inflammation. There are several challenges associated to profiling of such mediators, namely similar chemical structure with diverse biological functions as well as their low abundance in biological systems (13-15). This is further complicated by the dynamic biosynthesis of these molecular species that is time and cell-type dependent (4). Despite these challenges, several advancements related to the identification of novel mediators and the function of these mediators can be attributed to lipidomics approach, especially in animal models $(138,139)$. Computational and experimental models of bioactive lipid metabolism in human polymorphonuclear leukocytes has also been used to further assess the flux of these mediators in specific immune cells (140, 141). Although there have been several studies in animals, characterization of these lipid mediators in critical ill patients has not been established due to the additional complexity and heterogeneity of the patient population. Despite its complexity, lipidomics in critical illness has the potential not only to improve our understanding of the pathophysiological processes involved in generation and resolution of inflammation, but also to identify metabolic signatures or novel specific biomarkers for earlier diagnosis, better risk stratification and prediction of patient outcomes. Finally, it facilitates metabolic assessment providing valuable information for phenotyping and characterization of critically ill patients and may promote the steps towards precision medicine.

\section{AUTHOR CONTRIBUTIONS}

All authors contributed equally to the manuscript, writing sections of initial draft and then each revising other sections. Funding not applicable. All authors contributed to the article and approved the submitted version.

\section{SUPPLEMENTARY MATERIAL}

The Supplementary Material for this article can be found online at: https://www.frontiersin.org/articles/10.3389/fimmu.2020.599853/ full\#supplementary-material

5. Serhan CN. Novel lipid mediators and resolution mechanisms in acute inflammation: to resolve or not? Am J Pathol (2010) 177(4):1576-91. doi: 10.2353/ ajpath.2010.100322

6. Nathan C, Ding A. Nonresolving inflammation. Cell (2010) 140(6):871-82. doi: $10.1016 /$ j.cell.2010.02.029

7. Prescott HC, Calfee CS, Thompson BT, Angus DC, Liu VX. Toward SmarterLumping and Smarter Splitting: Rethinking Strategies for Sepsis and Acute Respiratory Distress Syndrome Clinical Trial Design. Am J Respir Crit Care Med (2016) 194(2):147-55. doi: 10.1164/rccm.201512$2544 \mathrm{CP}$ 
8. Buchman TG, Billiar TR, Elster E, Kirk AD, Rimawi RH, Vodovotz Y, et al. Precision Medicine for Critical Illness and Injury. Crit Care Med (2016) 44 (9):1635-8. doi: 10.1097/CCM.0000000000002028

9. Christaki E, Giamarellos-Bourboulis EJ. The beginning of personalized medicine in sepsis: small steps to a bright future. Clin Genet (2014) 86 (1):56-61. doi: $10.1111 /$ cge. 12368

10. Beitler JR, Goligher EC, Schmidt M, Spieth PM, Zanella A, Martin-Loeches I, et al. Personalized medicine for ARDS: the 2035 research agenda. Intensive Care Med (2016) 42(5):756-67. doi: 10.1007/s00134-016-4331-6

11. Maslove DM, Lamontagne F, Marshall JC. Heyland DK. A path to precision in the ICU. Crit Care (2017) 21(1):79. doi: 10.1186/s13054-017-1653-x

12. Davenport EE, Burnham KL, Radhakrishnan J, Humburg P, Hutton P, Mills TC, et al. Genomic landscape of the individual host response and outcomes in sepsis: a prospective cohort study. Lancet Respir Med (2016) 4(4):259-71. doi: 10.1016/S2213-2600(16)00046-1

13. Dumlao DS, Buczynski MW, Norris PC, Harkewicz R, Dennis EA. Highthroughput lipidomic analysis of fatty acid derived eicosanoids and $\mathrm{N}$ acylethanolamines. Biochim Biophys Acta (2011) 1811(11):724-36. doi: 10.1016/j.bbalip.2011.06.005

14. Masoodi M, Eiden M, Koulman A, Spaner D, Volmer DA. Comprehensive lipidomics analysis of bioactive lipids in complex regulatory networks. Anal Chem (2010) 82(19):8176-85. doi: 10.1021/ac1015563

15. Masoodi M, Volmer DA. Comprehensive quantitative determination of PUFA-related bioactive lipids for functional lipidomics using highresolution mass spectrometry. Methods Mol Biol (2014) 1198:221-32. doi: 10.1007/978-1-4939-1258-2_14

16. Kumar V. Sepsis roadmap: What we know, what we learned, and where we are going. Clin Immunol (2020) 210:108264. doi: 10.1016/j.clim.2019.108264

17. Patricio P, Paiva JA, Borrego LM. Immune Response in Bacterial and Candida Sepsis. Eur J Microbiol Immunol (Bp) (2019) 9(4):105-13. doi: $10.1556 / 1886.2019 .00011$

18. Tidball JG. Inflammatory processes in muscle injury and repair. Am J Physiol Regul Integr Comp Physiol (2005) 288(2):R345-53. doi: 10.1152/ajpregu. 00454.2004

19. Basil MC, Levy BD. Specialized pro-resolving mediators: endogenous regulators of infection and inflammation. Nat Rev Immunol (2016) 16 (1):51-67. doi: 10.1038/nri.2015.4

20. Peters-Golden M, Brock TG. Intracellular compartmentalization of leukotriene synthesis: unexpected nuclear secrets. FEBS Lett (2001) 487 (3):323-6. doi: 10.1016/s0014-5793(00)02374-7

21. Williams TJ, Peck MJ. Role of prostaglandin-mediated vasodilatation in inflammation. Nature (1977) 270(5637):530-2. doi: 10.1038/270530a0

22. Levy BD, Clish CB, Schmidt B, Gronert K, Serhan CN. Lipid mediator class switching during acute inflammation: signals in resolution. Nat Immunol (2001) 2(7):612-9. doi: 10.1038/89759

23. Bannenberg GL, Chiang N, Ariel A, Arita M, Tjonahen E, Gotlinger KH, et al. Molecular circuits of resolution: formation and actions of resolvins and protectins. J Immunol (2005) 174(7):4345-55. doi: 10.4049/jimmunol.174.7.4345

24. Serhan CN, Levy BD. Resolvins in inflammation: emergence of the proresolving superfamily of mediators. J Clin Invest (2018) 128(7):2657-69. doi: 10.1172/JCI97943

25. Buckley CD, Gilroy DW, Serhan CN. Proresolving lipid mediators and mechanisms in the resolution of acute inflammation. Immunity (2014) 40 (3):315-27. doi: 10.1016/j.immuni.2014.02.009

26. Gilroy D, De Maeyer R. New insights into the resolution of inflammation. Semin Immunol (2015) 27(3):161-8. doi: 10.1016/j.smim.2015.05.003

27. Funk CD. Prostaglandins and leukotrienes: advances in eicosanoid biology. Sci (New York NY) (2001) 294(5548):1871-5. doi: 10.1126/science.294.5548.1871

28. Serhan $\mathrm{CN}$. The resolution of inflammation: the devil in the flask and in the details. FASEB J Off Publ Fed Am Societies Exp Biol (2011) 25(5):1441-8. doi: 10.1096/fj.11-0502ufm

29. Serhan CN. Novel lipid mediators and resolution mechanisms in acute inflammation: to resolve or not? (1525-2191 (Electronic)). Am J Pathol. (2010) 177(4):1576-91. doi: 10.2353/ajpath.2010.100322

30. Nathan C, Ding A. Nonresolving inflammation. (1097-4172 (Electronic)). Cell (2010) 140(6):871-82. doi: 10.1016/j.cell.2010.02.029

31. Serhan CN, Savill J. Resolution of inflammation: the beginning programs the end. Nat Immunol (2005) 6(12):1191-7. doi: 10.1038/ni1276
32. Freire-de-Lima CG, Xiao YQ, Gardai SJ, Bratton DL, Schiemann WP, Henson PM. Apoptotic cells, through transforming growth factor-beta, coordinately induce anti-inflammatory and suppress pro-inflammatory eicosanoid and NO synthesis in murine macrophages. J Biol Chem (2006) 281(50):38376-84. doi: 10.1074/jbc.M605146200

33. Serhan CN, Clish CB, Brannon J, Colgan SP, Chiang N, Gronert K. Novel functional sets of lipid-derived mediators with antiinflammatory actions generated from omega-3 fatty acids via cyclooxygenase 2-nonsteroidal antiinflammatory drugs and transcellular processing. J Exp Med (2000) 192(8):1197-204. doi: 10.1084/jem.192.8.1197

34. Serhan CN, Yang R, Martinod K, Kasuga K, Pillai PS, Porter TF, et al. Maresins: novel macrophage mediators with potent antiinflammatory and proresolving actions. J Exp Med (2009) 206(1):15-23. doi: 10.1084/jem.20081880

35. Levy BD, Clish Cb Fau - Schmidt B, Schmidt B Fau - Gronert K, Gronert K Fau - Serhan CN, Serhan CN. Lipid mediator class switching during acute inflammation: signals in resolution. (1529-2908 (Print)). Nat Immunol (2001) 2(7):612-9. doi: 10.1038/89759

36. Medzhitov R. Inflammation 2010: new adventures of an old flame. Cell (2010) 140(6):771-6. doi: 10.1016/j.cell.2010.03.006

37. Gilroy DW, Edin ML, De Maeyer RP, Bystrom J, Newson J, Lih FB, et al. CYP450-derived oxylipins mediate inflammatory resolution. Proc Natl Acad Sci U.S.A. (2016) 113(23):E3240-9. doi: 10.1073/pnas.1521453113

38. Duvall MG, Levy BD. DHA- and EPA-derived resolvins, protectins, and maresins in airway inflammation. Eur J Pharmacol (2016) 785:144-55. doi: 10.1016/j.ejphar.2015.11.001

39. Singer M, Deutschman CS, Seymour CW, Shankar-Hari M, Annane D, Bauer M, et al. The Third International Consensus Definitions for Sepsis and Septic Shock (Sepsis-3). JAMA (2016) 315(8):801-10. doi: 10.1001/jama.2016.0287

40. Shankar-Hari M, Phillips GS, Levy ML, Seymour CW, Liu VX, Deutschman CS, et al. Developing a New Definition and Assessing New Clinical Criteria for Septic Shock: For the Third International Consensus Definitions for Sepsis and Septic Shock (Sepsis-3). JAMA (2016) 315(8):775-87. doi: 10.1001/jama.2016.0289

41. Seymour CW, Liu VX, Iwashyna TJ, Brunkhorst FM, Rea TD, Scherag A, et al. Assessment of Clinical Criteria for Sepsis: For the Third International Consensus Definitions for Sepsis and Septic Shock (Sepsis-3). JAMA (2016) 315(8):762-74. doi: 10.1001/jama.2016.0288

42. Chousterman BG, Swirski FK, Weber GF. Cytokine storm and sepsis disease pathogenesis. Semin Immunopathol (2017) 39(5):517-28. doi: 10.1007/ s00281-017-0639-8

43. Singer P, Blaser AR, Berger MM, Alhazzani W, Calder PC, Casaer MP, et al. ESPEN guideline on clinical nutrition in the intensive care unit. Clin Nutr (2019) 38(1):48-79. doi: 10.1016/j.clnu.2018.08.037

44. Chiang N, Fredman G, Backhed F, Oh SF, Vickery T, Schmidt BA, et al. Infection regulates pro-resolving mediators that lower antibiotic requirements. Nature (2012) 484(7395):524-8. doi: 10.1038/nature11042

45. Diaz LA, Altman NH, Khan W, Serhan CN, Adkins B. Specialized proresolving mediators rescue infant mice from lethal Citrobacter rodentium infection and promote immunity against reinfection. Infection Immun (2017) 85(10):e00464-17. doi: 10.1128/IAI.00464-17

46. Chiang N, de la Rosa X, Libreros S, Serhan CN. Novel Resolvin D2 Receptor Axis in Infectious Inflammation. J Immunol (2017) 198(2):842. doi: 10.4049/ jimmunol.1601650

47. Spite M, Serhan CN. Novel lipid mediators promote resolution of acute inflammation: impact of aspirin and statins. Circ Res (2010) 107(10):117084. doi: 10.1161/CIRCRESAHA.110.223883

48. Chiang N, Dalli J, Colas RA, Serhan CN. Identification of resolvin D2 receptor mediating resolution of infections and organ protection. J Exp Med (2015) 212(8):1203-17. doi: 10.1084/jem.20150225

49. Kurihara T, Jones CN, Yu YM, Fischman AJ, Watada S, Tompkins RG, et al. Resolvin D2 restores neutrophil directionality and improves survival after burns. FASEB J (2013) 27(6):2270-81. doi: 10.1096/fj.12-219519

50. Winkler JW, Orr SK, Dalli J, Cheng CY, Sanger JM, Chiang N, et al. Resolvin D4 stereoassignment and its novel actions in host protection and bacterial clearance. Sci Rep (2016) 6:18972. doi: 10.1038/srep18972

51. Spite M, Norling LV, Summers L, Yang R, Cooper D, Petasis NA, et al. Resolvin D2 is a potent regulator of leukocytes and controls microbial sepsis. Nature (2009) 461(7268):1287-91. doi: 10.1038/nature08541 
52. Hao Y, Zheng H, Wang R-H, Li H, Yang L-L, Bhandari S, et al. Maresin1 Alleviates Metabolic Dysfunction in Septic Mice: A 1H NMR-Based Metabolomics Analysis. Mediators Inflammation (2019) 2019:2309175. doi: 10.1155/2019/2309175

53. Gu J, Luo L, Wang Q, Yan S, Lin J, Li D, et al. Maresin 1 attenuates mitochondrial dysfunction through the ALX/cAMP/ROS pathway in the cecal ligation and puncture mouse model and sepsis patients. Lab Invest (2018) 98(6):715-33. doi: 10.1038/s41374-018-0031-x

54. Wu B, Walker J, Spur B, Rodriguez A, Yin K. Effects of Lipoxin A4 on antimicrobial actions of neutrophils in sepsis. Prostaglandins Leukot Essent Fatty Acids (2015) 94:55-64. doi: 10.1016/j.plefa.2014.11.005

55. Ueda T, Fukunaga K, Seki H, Miyata J, Arita M, Miyasho T, et al. Combination therapy of 15-epi-lipoxin a4 with antibiotics protects mice from escherichia coli-induced sepsis. Crit Care Med (2014) 42(4):e288-95. doi: 10.1097/CCM.0000000000000162

56. Walker J, Dichter E, Lacorte G, Kerner D, Spur B, Rodriguez A, et al. Lipoxin a4 increases survival by decreasing systemic inflammation and bacterial load in sepsis. Shock (2011) 36(4):410-6. doi: 10.1097/SHK.0b013e31822798c1

57. Wu B, Capilato J, Pham MP, Walker J, Spur B, Rodriguez A, et al. Lipoxin A4 augments host defense in sepsis and reduces Pseudomonas aeruginosa virulence through quorum sensing inhibition. FASEB J (2016) 30(6):240010. doi: $10.1096 /$ fj.201500029R

58. Sordi R, Menezes-de-Lima OJr., Horewicz V, Scheschowitsch K, Santos LF, Assreuy J. Dual role of lipoxin A4 in pneumosepsis pathogenesis. Int Immunopharmacol (2013) 17(2):283-92. doi: 10.1016/j.intimp.2013.06.010

59. Tsai WH, Shih CH, Yu YB, Hsu HC. Plasma levels in sepsis patients of annexin A1, lipoxin A4, macrophage inflammatory protein-3a, and neutrophil gelatinase-associated lipocalin. J Chin Med Assoc (2013) 76 (9):486-90. doi: 10.1016/j.jcma.2013.05.004

60. Cioccari L, Luethi N, Duong T, Ryan E, Cutuli SL, Lloyd-Donald P, et al. Cytokine and lipid metabolome effects of low-dose acetylsalicylic acid in critically ill patients with systemic inflammation: a pilot, feasibility, multicentre, randomised, placebo-controlled trial. Crit Care Resusc (2020) 22(3):227-36.

61. Dalli J, Colas RA, Quintana C, Barragan-Bradford D, Hurwitz S, Levy BD, et al. Human Sepsis Eicosanoid and Proresolving Lipid Mediator Temporal Profiles: Correlations With Survival and Clinical Outcomes. Crit Care Med (2017) 45(1):58-68. doi: 10.1097/ccm.0000000000002014

62. Kor DJ, Carter RE, Park PK, Festic E, Banner-Goodspeed VM, Hinds R, et al. Effect of Aspirin on Development of ARDS in At-Risk Patients Presenting to the Emergency Department: The LIPS-A Randomized Clinical Trial. JAMA (2016) 315(22):2406-14. doi: 10.1001/jama.2016.6330

63. Abdulnour RE, Gunderson T, Barkas I, Timmons JY, Barnig C, Gong M, et al. Early Intravascular Events Are Associated with Development of Acute Respiratory Distress Syndrome. A Substudy of the LIPS-A Clinical Trial. Am J Respir Crit Care Med (2018) 197(12):1575-85. doi: 10.1164/rccm.2017122530OC

64. Masclans JR, Bermejo B, Picó M, de Latorre FJ, Rodríguez-Roisin R, Planas $\mathrm{M}$. [The prognostic value of eicosanoids in the acute respiratory distress syndrome]. Med Clin (Barc) (1999) 112(3):81-4.

65. Masclans JR, Sabater J, Sacanell J, Chacon P, Sabin P, Roca O, et al. Possible prognostic value of leukotriene $\mathrm{B}(4)$ in acute respiratory distress syndrome. Respir Care (2007) 52(12):1695-700.

66. Pilitsis JG, Coplin WM, O’Regan MH, Wellwood JM, Diaz FG, Fairfax MR, et al. Free fatty acids in cerebrospinal fluids from patients with traumatic brain injury. Neurosci Lett (2003) 349(2):136-8. doi: 10.1016/s0304-3940 (03)00803-6

67. Auner B, Geiger EV, Henrich D, Lehnert M, Marzi I, Relja B. Circulating leukotriene B4 identifies respiratory complications after trauma. Mediators Inflammation (2012) 2012:536156. doi: 10.1155/2012/536156

68. Orr SK, Butler KL, Hayden D, Tompkins RG, Serhan CN, Irimia D. Gene Expression of Proresolving Lipid Mediator Pathways Is Associated With Clinical Outcomes in Trauma Patients. Crit Care Med (2015) 43(12):264250. doi: $10.1097 / \mathrm{ccm} .0000000000001312$

69. Chiang N, Bermudez EA, Ridker PM, Hurwitz S, Serhan CN. Aspirin triggers antiinflammatory 15-epi-lipoxin A4 and inhibits thromboxane in a randomized human trial. Proc Natl Acad Sci U.S.A. (2004) 101(42):1517883. doi: $10.1073 /$ pnas. 0405445101
70. Ranieri VM, Rubenfeld GD, Thompson BT, Ferguson ND, Caldwell E, Fan E, et al. Acute Respiratory Distress Syndrome: The Berlin Definition. JAMA (2012) 307(23):2526-33. doi: 10.1001/jama.2012.5669

71. Huppert LA, Matthay MA, Ware LB. Pathogenesis of Acute Respiratory Distress Syndrome. Semin Respir Crit Care Med (2019) 40(1):31-9. doi: 10.1055/s-0039-1683996

72. Levy BD, Serhan CN. Resolution of acute inflammation in the lung. Annu Rev Physiol (2014) 76:467-92. doi: 10.1146/annurev-physiol-021113-170408

73. Gao D, Zhang L, Song D, Lv J, Wang L, Zhou S, et al. Values of integration between lipidomics and clinical phenomes in patients with acute lung infection, pulmonary embolism, or acute exacerbation of chronic pulmonary diseases: a preliminary study. J Transl Med (2019) 17(1):162. doi: 10.1186/s12967-019-1898-z

74. Colby JK, Abdulnour RE, Sham HP, Dalli J, Colas RA, Winkler JW, et al. Resolvin D3 and Aspirin-Triggered Resolvin D3 Are Protective for Injured Epithelia. Am J Pathol (2016) 186(7):1801-13. doi: 10.1016/j.ajpath.2016.03.011

75. Abdulnour RE, Dalli J, Colby JK, Krishnamoorthy N, Timmons JY, Tan SH, et al. Maresin 1 biosynthesis during platelet-neutrophil interactions is organprotective. Proc Natl Acad Sci U.S.A. (2014) 111(46):16526-31. doi: 10.1073/ pnas. 1407123111

76. Xia H, Wang J, Sun S, Wang F, Yang Y, Chen L, et al. Resolvin D1 Alleviates Ventilator-Induced Lung Injury in Mice by Activating PPAR $\gamma / \mathrm{NF}-\kappa \mathrm{B}$ Signaling Pathway. BioMed Res Int (2019) 2019:6254587. doi: 10.1155/ 2019/6254587

77. Yang Y, Hu L, Xia H, Chen L, Cui S, Wang Y, et al. Resolvin D1 attenuates mechanical stretch-induced pulmonary fibrosis via epithelial-mesenchymal transition. Am J Physiol Lung Cell Mol Physiol (2019) 316(6):L1013-11024. doi: 10.1152/ajplung.00415.2018

78. Wang B, Gong X, Wan JY, Zhang L, Zhang Z, Li HZ, et al. Resolvin D1 protects mice from LPS-induced acute lung injury. Pulm Pharmacol Ther (2011) 24(4):434-41. doi: 10.1016/j.pupt.2011.04.001

79. Eickmeier O, Seki H, Haworth O, Hilberath JN, Gao F, Uddin M, et al. Aspirin-triggered resolvin D1 reduces mucosal inflammation and promotes resolution in a murine model of acute lung injury. Mucosal Immunol (2013) 6(2):256-66. doi: 10.1038/mi.2012.66

80. Mayer K, Sommer N, Hache K, Hecker A, Reiche S, Schneck E, et al. Resolvin E1 Improves Mitochondrial Function in Human Alveolar Epithelial Cells during Severe Inflammation. Lipids (2019) 54(1):53-65. doi: 10.1002/ lipd.12119

81. Seki H, Fukunaga K, Arita M, Arai H, Nakanishi H, Taguchi R, et al. The anti-inflammatory and proresolving mediator resolvin E1 protects mice from bacterial pneumonia and acute lung injury. J Immunol (Baltimore $\mathrm{Md}$ 1950) (2010) 184(2):836-43. doi: 10.4049/jimmunol.0901809

82. El Kebir D, Gjorstrup P, Filep JG. Resolvin E1 promotes phagocytosisinduced neutrophil apoptosis and accelerates resolution of pulmonary inflammation. Proc Natl Acad Sci U.S.A. (2012) 109(37):14983-8. doi: 10.1073/pnas.1206641109

83. Morita M, Kuba K, Ichikawa A, Nakayama M, Katahira J, Iwamoto R, et al. The lipid mediator protectin D1 inhibits influenza virus replication and improves severe influenza. Cell (2013) 153(1):112-25. doi: 10.1016/j.cell.2013.02.027

84. Sham HP, Walker KH, Abdulnour RE, Krishnamoorthy N, Douda DN, Norris PC, et al. 15-epi-Lipoxin A(4), Resolvin D2, and Resolvin D3 Induce NF- $\mathrm{BB}$ Regulators in Bacterial Pneumonia. J Immunol (2018) 200(8):275766. doi: 10.4049/jimmunol.1602090

85. El Kebir D, Jozsef L, Pan W, Wang L, Petasis NA, Serhan CN, et al. 15-epilipoxin A4 inhibits myeloperoxidase signaling and enhances resolution of acute lung injury. Am J Respir Crit Care Med (2009) 180(4):311-9. doi: 10.1164/rccm.200810-1601OC

86. Haagsma JA, Graetz N, Bolliger I, Naghavi M, Higashi H, Mullany EC, et al. The global burden of injury: incidence, mortality, disability-adjusted life years and time trends from the Global Burden of Disease study 2013. Inj Prev (2016) 22(1):3-18. doi: 10.1136/injuryprev-2015-041616

87. Søreide K. Epidemiology of major trauma. Br J Surg (2009) 96(7):697-8. doi: 10.1002/bjs.6643

88. Eiden M, Christinat N, Chakrabarti A, Sonnay S, Miroz JP, Cuenoud B, et al. Discovery and validation of temporal patterns involved in human brain ketometabolism in cerebral microdialysis fluids of traumatic brain injury patients. EBioMedicine (2019) 44:607-17. doi: 10.1016/j.ebiom.2019.05.054 
89. Stocchetti N, Carbonara M, Citerio G, Ercole A, Skrifvars MB, Smielewski P, et al. Severe traumatic brain injury: targeted management in the intensive care unit. Lancet Neurol (2017) 16(6):452-64. doi: 10.1016/S1474-4422(17) 30118-7

90. Chow CC, Clermont G, Kumar R, Lagoa C, Tawadrous Z, Gallo D, et al. The acute inflammatory response in diverse shock states. Shock (2005) 24(1):7484. doi: 10.1097/01.shk.0000168526.97716.f3

91. Ioannou A, Dalle Lucca J, Tsokos GC. Immunopathogenesis of ischemia/ reperfusion-associated tissue damage. Clin Immunol (2011) 141(1):3-14. doi: 10.1016/j.clim.2011.07.001

92. Søreide K. Clinical and translational aspects of hypothermia in major trauma patients: from pathophysiology to prevention, prognosis and potential preservation. Injury (2014) 45(4):647-54. doi: 10.1016/j.injury.2012.12.027

93. Simsek T, Simsek HU, Canturk NZ. Response to trauma and metabolic changes: posttraumatic metabolism. Ulus Cerrahi Derg (2014) 30(3):153-9. doi: 10.5152/ucd.2014.2653

94. Cohen MJ, Serkova NJ, Wiener-Kronish J, Pittet JF, Niemann CU. 1HNMR-based metabolic signatures of clinical outcomes in trauma patientsbeyond lactate and base deficit. J Trauma (2010) 69(1):31-40. doi: 10.1097/ TA.0b013e3181e043fe

95. Lasseigne LM, Belayev L, Khoutorova L, Obenaus A, Rossi J, Petasis NA, et al. Elovanoids, a novel class of lipid mediators, protect brain after traumatic brain injury. J Neurotrauma (2018) 35(16):A228. doi: 10.1089/ neu.2018.29013.abstracts

96. Belayev L, Obenaus A, Petasis NA, Khoutorova L, Bazan NG. A novel class of lipid mediators, elovanoids, improve behavior and preserve brain tissue after traumatic brain injury in rats. J Cereb Blood Flow Metab (2019) 39(1 Supplement):306-7. doi: 10.1177/0271678X19851020

97. Bisicchia E, Sasso V, Catanzaro G, Leuti A, Besharat ZM, Chiacchiarini M, et al. Resolvin D1 Halts Remote Neuroinflammation and Improves Functional Recovery after Focal Brain Damage Via ALX/FPR2 ReceptorRegulated MicroRNAs. Mol Neurobiol (2018) 55(8):6894-905. doi: 10.1007/ s12035-018-0889-z

98. Harrison JL, Rowe RK, Ellis TW, Yee NS, O'Hara BF, Adelson PD, et al. Resolvins AT-D1 and E1 differentially impact functional outcome, posttraumatic sleep, and microglial activation following diffuse brain injury in the mouse. Brain Behav Immun (2015) 47(1090-2139(1090-2139 (Electronic):131-40. doi: 10.1016/j.bbi.2015.01.001

99. Thau-Zuchman O, Ingram R, Harvey GG, Cooke T, Palmas F, Pallier PN, et al. A Single Injection of Docosahexaenoic Acid Induces a Pro-Resolving Lipid Mediator Profile in the Injured Tissue and a Long-Lasting Reduction in Neurological Deficit after Traumatic Brain Injury in Mice. J Neurotrauma (2020) 37(1):66-79. doi: 10.1089/neu.2019.6420

100. Schober ME, Requena DF, Casper TC, Velhorst AK, Lolofie A, McFarlane $\mathrm{KE}$, et al. Docosahexaenoic acid decreased neuroinflammation in rat pups after controlled cortical impact. Exp Neurol (2019) 320(1090-2430(10902430 (Electronic):112971. doi: 10.1016/j.expneurol.2019.112971

101. Bailes JE, Mills JD. Docosahexaenoic acid reduces traumatic axonal injury in a rodent head injury model. J Neurotrauma (2010) 27(9):1617-24. doi: 10.1089/ neu.2009.1239

102. Tian Z-R, Yao M, Zhou L-Y, Song Y-J, Ye J, Wang Y-J, et al. Effect of docosahexaenoic acid on the recovery of motor function in rats with spinal cord injury: a meta-analysis. Neural Regener Res (2020) 15(3):537-47. doi: 10.4103/1673-5374.266065

103. Hall JC, Priestley JV, Perry VH, Michael-Titus AT. Docosahexaenoic acid, but not eicosapentaenoic acid, reduces the early inflammatory response following compression spinal cord injury in the rat. J Neurochem (2012) 121 (5):738-50. doi: 10.1111/j.1471-4159.2012.07726.x

104. Francos-Quijorna I, Santos-Nogueira E, Gronert K, Sullivan AB, Kopp MA, Brommer B, et al. Maresin 1 Promotes Inflammatory Resolution, Neuroprotection, and Functional Neurological Recovery After Spinal Cord Injury. J Neurosci (2017) 37(48):11731-43. doi: 10.1523/jneurosci.1395-17.2017

105. Ji J, Baart S, Vikulina AS, Clark RSB, Anthonymuthu TS, Tyurin VA, et al. Deciphering of mitochondrial cardiolipin oxidative signaling in cerebral ischemia-reperfusion. J Cereb Blood Flow Metab (2015) 35(2):319-28. doi: $10.1038 /$ jcbfm. 2014.204

106. Shaik JSB, Poloyac SM, Kochanek PM, Alexander H, Tudorascu DL, Clark RSB, et al. 20-Hydroxyeicosatetraenoic Acid Inhibition by HET0016 Offers
Neuroprotection, Decreases Edema, and Increases Cortical Cerebral Blood Flow in a Pediatric Asphyxial Cardiac Arrest Model in Rats. J Cereb Blood Flow Metab (2015) 35(11):1757-63. doi: 10.1038/jcbfm.2015.117

107. Yin P, Wei Y, Wang X, Zhu M, Feng J. Roles of Specialized Pro-Resolving Lipid Mediators in Cerebral Ischemia Reperfusion Injury. Front Neurol (2018) 9:617. doi: 10.3389/fneur.2018.00617

108. Zuo G, Zhang D, Mu R, Shen H, Li X, Wang Z, et al. Resolvin D2 protects against cerebral ischemia/reperfusion injury in rats. Mol Brain (2018) 11 (1):9. doi: 10.1186/s13041-018-0351-1

109. Bisicchia E, Sasso V, Catanzaro G, Leuti A, Besharat ZM, Chiacchiarini M, et al. Resolvin D1 Halts Remote Neuroinflammation and Improves Functional Recovery after Focal Brain Damage Via ALX/FPR2 ReceptorRegulated MicroRNAs. , (1559-1182 (Electronic)). Mol Neurobiol (2018) 55 (8):6894-905. doi: 10.1007/s12035-018-0889-z

110. Bazan NG, Eady TN, Khoutorova L, Atkins KD, Hong S, Lu Y, et al. Novel aspirin-triggered neuroprotectin D1 attenuates cerebral ischemic injury after experimental stroke. Exp Neurol (2012) 236(1):122-30. doi: 10.1016/ j.expneurol.2012.04.007

111. Belayev L, Mukherjee PK, Balaszczuk V, Calandria JM, Obenaus A, Khoutorova L, et al. Neuroprotectin D1 upregulates Iduna expression and provides protection in cellular uncompensated oxidative stress and in experimental ischemic stroke. Cell Death Differ (2017) 24(6):1091-9. doi: 10.1038/cdd.2017.55

112. Belayev L, Hong SH, Menghani H, Marcell SJ, Obenaus A, Freitas RS, et al. Docosanoids Promote Neurogenesis and Angiogenesis, Blood-Brain Barrier Integrity, Penumbra Protection, and Neurobehavioral Recovery After Experimental Ischemic Stroke. Mol Neurobiol (2018) 55(8):7090-106. doi: 10.1007/s12035-018-1136-3

113. Belayev L, Khoutorova L, Atkins KD, Bazan NG. Robust docosahexaenoic acid-mediated neuroprotection in a rat model of transient, focal cerebral ischemia. Stroke (2009) 40(9):3121-6. doi: 10.1161/strokeaha.109.555979

114. Eady TN, Belayev L, Khoutorova L, Atkins KD, Zhang C, Bazan NG. Docosahexaenoic acid signaling modulates cell survival in experimental ischemic stroke penumbra and initiates long-term repair in young and aged rats. PloS One (2012) 7(10):e46151. doi: 10.1371/journal.pone.0046151

115. Simonis G, Strasser RH, Ebner B. Reperfusion injury in acute myocardial infarction. Crit Care (2012) 16(Suppl 2):A22-2. doi: 10.1186/cc11280

116. Nithipatikom K, DiCamelli RF, Kohler S, Gumina RJ, Falck JR, Campbell WB, et al. Determination of cytochrome P450 metabolites of arachidonic acid in coronary venous plasma during ischemia and reperfusion in dogs. Anal Biochem (2001) 292(1):115-24. doi: 10.1006/abio.2001.5044

117. Granville DJ, Tashakkor B, Takeuchi C, Gustafsson AB, Huang C, Sayen MR, et al. Reduction of ischemia and reperfusion-induced myocardial damage by cytochrome P450 inhibitors. Proc Natl Acad Sci U.S.A. (2004) 101(5):1321-6. doi: $10.1073 /$ pnas. 0308185100

118. Gross GJ, Hsu A, Falck JR, Nithipatikom K. Mechanisms by which epoxyeicosatrienoic acids (EETs) elicit cardioprotection in rat hearts. J Mol Cell Cardiol (2007) 42(3):687-91. doi: 10.1016/j.yjmcc.2006.11.020

119. Batchu SN, Law E, Brocks DR, Falck JR, Seubert JM. Epoxyeicosatrienoic acid prevents postischemic electrocardiogram abnormalities in an isolated heart model. J Mol Cell Cardiol (2009) 46(1):67-74. doi: 10.1016/j.yjmcc.2008.09.711

120. Gross GJ, Gauthier KM, Moore J, Falck JR, Hammock BD, Campbell WB, et al. Effects of the selective EET antagonist, 14,15-EEZE, on cardioprotection produced by exogenous or endogenous EETs in the canine heart. Am J Physiol Heart Circ Physiol (2008) 294(6):H2838-44. doi: 10.1152/ajpheart.00186.2008

121. Motoki A, Merkel MJ, Packwood WH, Cao Z, Liu L, Iliff J, et al. Soluble epoxide hydrolase inhibition and gene deletion are protective against myocardial ischemia-reperfusion injury in vivo. Am J Physiol Heart Circ Physiol (2008) 295(5):H2128-34. doi: 10.1152/ajpheart.00428.2008

122. Seubert JM, Sinal CJ, Graves J, DeGraff LM, Bradbury JA, Lee CR, et al. Role of soluble epoxide hydrolase in postischemic recovery of heart contractile function. Circ Res (2006) 99(4):442-50. doi: 10.1161/01.Res.0000237390.92932.37

123. Kain V, Liu F, Kozlovskaya V, Ingle KA, Bolisetty S, Agarwal A, et al. Resolution Agonist 15-epi-Lipoxin A4 Programs Early Activation of Resolving Phase in Post-Myocardial Infarction Healing. Sci Rep (2017) 7 (1):9999. doi: 10.1038/s41598-017-10441-8

124. Kain V, Ingle KA, Colas RA, Dalli J, Prabhu SD, Serhan CN, et al. Resolvin D1 activates the inflammation resolving response at splenic and ventricular site 
following myocardial infarction leading to improved ventricular function. J Mol Cell Cardiol (2015) 84:24-35. doi: 10.1016/j.yjmcc.2015.04.003

125. Halade GV, Kain V, Serhan CN. Immune responsive resolvin D1 programs myocardial infarction-induced cardiorenal syndrome in heart failure. FASEB $J$ (2018) 32(7):3717-29. doi: 10.1096/fj.201701173RR

126. Keyes KT, Ye Y, Lin Y, Zhang C, Perez-Polo JR, Gjorstrup P, et al. Resolvin El protects the rat heart against reperfusion injury. Am J Physiol Heart Circ Physiol (2010) 299(1):H153-64. doi: 10.1152/ajpheart.01057.2009

127. Ronco C, Bellomo R, Kellum JA. Acute kidney injury. Lancet (2019) 394 (10212):1949-64. doi: 10.1016/s0140-6736(19)32563-2

128. Rao S, Walters KB, Wilson L, Chen B, Bolisetty S, Graves D, et al. Early lipid changes in acute kidney injury using SWATH lipidomics coupled with MALDI tissue imaging. Am J Physiol - Renal Physiol (2016) 310(10):F113647. doi: 10.1152 /ajprenal.00100.2016

129. Stasi A, Intini A, Divella C, Franzin R, Montemurno E, Grandaliano G, et al. Emerging role of Lipopolysaccharide binding protein in sepsis-induced acute kidney injury. Nephrol Dial Transplant (2017) 32(1):24-31. doi: 10.1093/ndt/gfw250

130. Wang S, Xiao C, Liu C, Li J, Fang F, Lu X, et al. Identification of Biomarkers of Sepsis-Associated Acute Kidney Injury in Pediatric Patients Based on UPLCQTOF/MS. Inflammation (2020) 43(2):629-40. doi: 10.1007/s10753-019-01144-5

131. Kasuga K, Yang R, Porter TF, Agrawal N, Petasis NA, Irimia D, et al. Rapid appearance of resolvin precursors in inflammatory exudates: novel mechanisms in resolution. J Immunol (2008) 181(12):8677-87. doi: 10.4049/jimmunol.181.12.8677

132. Duffield JS, Hong S, Vaidya VS, Lu Y, Fredman G, Serhan CN, et al. Resolvin D series and protectin D1 mitigate acute kidney injury. J Immunol (2006) 177 (9):5902-11. doi: 10.4049/jimmunol.177.9.5902

133. Zhao YL, Zhang L, Yang YY, Tang Y, Zhou JJ, Feng YY, et al. Resolvin D1 Protects Lipopolysaccharide-induced Acute Kidney Injury by Downregulating Nuclear Factor-kappa B Signal and Inhibiting Apoptosis. Chin Med J (Engl) (2016) 129(9):1100-7. doi: 10.4103/0366-6999.180517

134. Chen J, Shetty S, Zhang P, Gao R, Hu Y, Wang S, et al. Aspirin-triggered resolvin D1 down-regulates inflammatory responses and protects against endotoxin-induced acute kidney injury. Toxicol Appl Pharmacol (2014) 277 (2):118-23. doi: 10.1016/j.taap.2014.03.017
135. Efron PA, Mohr AM, Moore FA, Moldawer LL. The future of murine sepsis and trauma research models. J Leukoc Biol (2015) 98(6):945-52. doi: $10.1189 / \mathrm{jlb} .5 \mathrm{MR} 0315-127 \mathrm{R}$

136. Seok J, Warren HS, Cuenca AG, Mindrinos MN, Baker HV, Xu W, et al. Genomic responses in mouse models poorly mimic human inflammatory diseases. Proc Natl Acad Sci U.S.A. (2013) 110(9):3507-12. doi: 10.1073/pnas.1222878110

137. Warren HS, Tompkins RG, Moldawer LL, Seok J, Xu W, Mindrinos MN, et al. Mice are not men. Proc Natl Acad Sci U.S.A. (2015) 112(4):E345. doi: $10.1073 /$ pnas. 1414857111

138. Takano T, Fiore S, Maddox JF, Brady HR, Petasis NA, Serhan CN. Aspirintriggered 15-epi-lipoxin A4 (LXA4) and LXA4 stable analogues are potent inhibitors of acute inflammation: evidence for anti-inflammatory receptors. J Exp Med (1997) 185(9):1693-704. doi: 10.1084/jem.185.9.1693

139. Schwab JM, Serhan CN. Lipoxins and new lipid mediators in the resolution of inflammation. Curr Opin Pharmacol (2006) 6(4):414-20. doi: 10.1016/ j.coph.2006.02.006

140. Yang K, Ma W, Liang H, Ouyang Q, Tang C, Lai L. Dynamic simulations on the arachidonic acid metabolic network. PloS Comput Biol (2007) 3(3):e55. doi: 10.1371/journal.pcbi.0030055

141. Kihara Y, Gupta S, Maurya MR, Armando A, Shah I, Quehenberger O, et al. Modeling of eicosanoid fluxes reveals functional coupling between cyclooxygenases and terminal synthases. Biophys J (2014) 106(4):966-75. doi: 10.1016/j.bpj.2014.01.015

Conflict of Interest: The authors declare that the research was conducted in the absence of any commercial or financial relationships that could be construed as a potential conflict of interest.

Copyright (c) 2020 Cioccari, Luethi and Masoodi. This is an open-access article distributed under the terms of the Creative Commons Attribution License (CC BY). The use, distribution or reproduction in other forums is permitted, provided the original author(s) and the copyright owner(s) are credited and that the original publication in this journal is cited, in accordance with accepted academic practice. No use, distribution or reproduction is permitted which does not comply with these terms. 